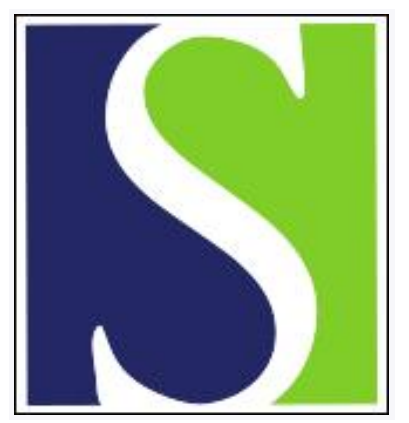

Scand J Work Environ Health 2005;31(1):3-14

https://doi.org/10.5271/sjweh.843

Issue date: Feb 2005

Different mechanisms to explain the reversed effects of mental health on work characteristics

by de Lange AH, Taris TW, Kompier MAJ, Houtman ILD, Bongers PM

Affiliation: Vrije Universiteit Amsterdam, Department of Management and Organization, Faculty of Economics and Business Administration, room 3A-34, 1081 HV Amsterdam, The Netherlands. alange@feweb.vu.nl

The following articles refer to this text: 2006;32(6):443-462; 2007;33(1):29-36; 2011;37(4):259-261; 2011;37(5):359-362; 2013;39(6):535-549; 2014;40(5):441-456; 2014;40(5):437-440; 2017;43(4):316-325; 2020;46(5):469-479; 2023;49(1):64-74

Key terms: drift mechanism; gloomy perception mechanism; longitudinal research; mental health; reversed causation; reversed effect; rosy perception mechanism; upward selection mechanism; work characteristic

This article in PubMed: www.ncbi.nlm.nih.gov/pubmed/15751614 


\title{
Different mechanisms to explain the reversed effects of mental health on work characteristics
}

\author{
by Annet H de Lange, MA, ${ }^{1,2}$ Toon W Taris, PhD, ${ }^{1}$ Michiel AJ Kompier, PhD, ${ }^{1}$ Irene LD Houtman, PhD, ${ }^{3}$ \\ Paulien M Bongers, $P h D^{3,4}$
}

de Lange A, Taris TW, Kompier MAJ, Houtman ILD, Bongers PM. Different mechanisms to explain the reversed effects of mental health on work characteristics. Scand J Work Environ Health 2005;31(1):3-14.

\begin{abstract}
Objectives The number of longitudinal studies reporting evidence for reversed effects of strain on work is growing, but evidence regarding the mechanisms underlying such effects is scarce. In this study, earlier longitudinal findings were reviewed, and the following four mechanisms for reversed effects were proposed that reflect within-person or environmental changes: (i) the rosy perception mechanism, (ii) the gloomy perception mechanism, (iii) the upward selection mechanism, and (iv) the drift mechanism.

Methods These mechanisms were tested using structural equation modeling and longitudinal data from a Dutch four-phase study ( $\mathrm{N}=1588$ participants).

Results The results revealed that work characteristics and mental health influenced each other reciprocally and longitudinally. The reversed effects were examined in more detail, and it was found that these could be accounted for by both within-person and environmental change mechanisms. The rosy perception mechanism was found to explain the positive effects from health on job demands; the upward selection mechanism explained the positive (environmental) effects from health on job control; the gloomy perception mechanism explained the reversed (evaluation) effects from health on supervisory social support. No support was found for the drift mechanism.

Conclusions Mechanisms that may explain reversed causation are yet poorly understood. The main contribution of the present study lies in the fact that it proposes (i) a conceptual framework with which to analyze the effects of health on work characteristics and (ii) methods for testing these mechanisms. The study revealed that there is good reason to pursue research on reversed causality.
\end{abstract}

Key terms drift mechanism; gloomy perception mechanism; research, longitudinal; mental health; reversed causation; rosy perception mechanism; upward selection mechanism.

One goal of occupational health research is to determine the causal sequence of the relationship between work and well-being (1). Most work-stress models, for example, the demand-control-support (DCS) model (2), consider this relationship to be unidirectional. Stressful work, characterized by, for example, high demands, low control, and low social support, is assumed to lead to such strain complaints as diminished psychological and physical well-being. These normal causal relationships have been documented in numerous studies. [See de Lange et al (3) and Van der Doef \& Maes (4) for reviews.] However, the cross-sectional associations between work and strain typically reported in previous research can also be explained by reversed causal relationships, in which initial strain complaints influence work characteristics across time. For instance, a tired time-1 employee may perceive his or her time-2 job demands as more demanding than an energetic time- 1 coworker. Associations between work and strain can also be explained by bi-directional or reciprocal causal relationships in which both normal and reversed causal relationships operate $(5,6)$. A recent longitudinal study (7) found evidence for reciprocal causal relationships between the demands, control, and social support of supervisors on one hand and mental health (depressive mood, job satisfaction, and emotional exhaustion) on the

1 Radboud University of Nijmegen, Nijmegen, The Netherlands.

2 Vrije Universiteit Amsterdam, Amsterdam, The Netherlands.

3 TNO Work and Employment, Hoofddorp, The Netherlands.

4 Body@work, Research Center on Physical Activity, Work and Health TNO-VU, Amsterdam, The Netherlands.

Correspondence to: AH de Lange, Vrije Universiteit Amsterdam, Department of Management and Organization, Faculty of Economics and Business Administration, room 3A-34, 1081 HV Amsterdam, The Netherlands. [E-mail: alange@ feweb.vu.nl] 
other. These relationships were consistent across four time segments covering 3 years.

Although researchers are becoming increasingly aware of the possible reversed effects of mental health on work, such effects are rarely tested. Consequently, it is not known which mechanisms may account for them $(3,8)$. To enhance the understanding of reversed causation, in our present study, we have addressed the evidence and possible explanations for the effects of mental health on psychosocial work characteristics. First, we have briefly reviewed the evidence for and prevalence of these reversed effects and then considered four possible mechanisms that may account for reversed causation. Thereafter the results of our empirical testing of the mechanisms have been presented.

\section{Prevalence of reversed or reciprocal effects}

In reviewing the evidence for reversed effects, we focused on studies that measure the same variables repeatedly among the same panel of respondents, as only such studies can test reciprocal effects. Zapf et al (9) reviewed 39 longitudinal organizational stress studies and examined whether these studies tested normal or reversed effects. They found that 15 of the 39 stress studies explored reversed causal effects. Seven of the fifteen studies (47\%) provided evidence for reversed causal relationships. Typical examples are Kohn \& Schooler (10), who found a positive reversed effect of time-1 anxiety on time-2 self-reported time pressure (and not vice versa), and Marcelissen et al (11), who reported a negative reversed effect of health complaints (eg, strain, worry, and diastolic blood pressure) on co-worker support (and not vice versa).

More recently, four longitudinal studies (12-15) found effects of burnout levels on the perception of work characteristics. Bakker et al (12) found positive effects of time- 1 depersonalization on the time- 2 frequency and self-reported intensity of patient demands (but not vice versa), whereas de Jonge et al (13) reported a positive effect of emotional exhaustion on job demands (and not vice versa). Similar effects were found by Leiter \& Durup (14), who reported evidence for a reversed relationship between emotional exhaustion, work overload, and supervisory support, and Mills \& Huebner (15), who reported reversed effects of burnout on occupational stressors.

Longitudinal research also revealed effects of general distress or depressive complaints on the perception of work characteristics. Moyle (16) found positive effects of time- 1 distress on the perception of time- 2 demands, whereas, in addition to normal causal effects, Garst et al (17) found effects from time-1 strain (depressive complaints, psychosomatic complaints, irritation, and worrying) on the perception of time- 2 work stressors (job insecurity, time pressure, organizational problems, social stressors, and uncertainty). Three other longitudinal studies (18-20) found evidence for effects of prior depression on the perception of time- 2 job characteristics. Finally, Taris (21) found effects of mental health status (depression, self-esteem, and general health) on the perception of job characteristics (eg, variety, autonomy, and job security). On the basis of the results of these studies, it can be concluded that the evidence for lagged reciprocal relationships between work and (mental) health is accumulating. In other words, not only do work characteristics affect (mental) health, but (mental) health affects work characteristics as well.

How can these reversed effects be explained? Currently, little theorizing on possible underlying mechanisms is available. Figure 1 illustrates four mechanisms that we believe may be responsible for the reversed causal effect of mental health on work. Theoretically, reversed effects of mental health status can be due to

\section{Time 1 health status}

$$
\begin{aligned}
& \text { Type of } \\
& \text { change }
\end{aligned}
$$

Mechanism

Time 2 outcome

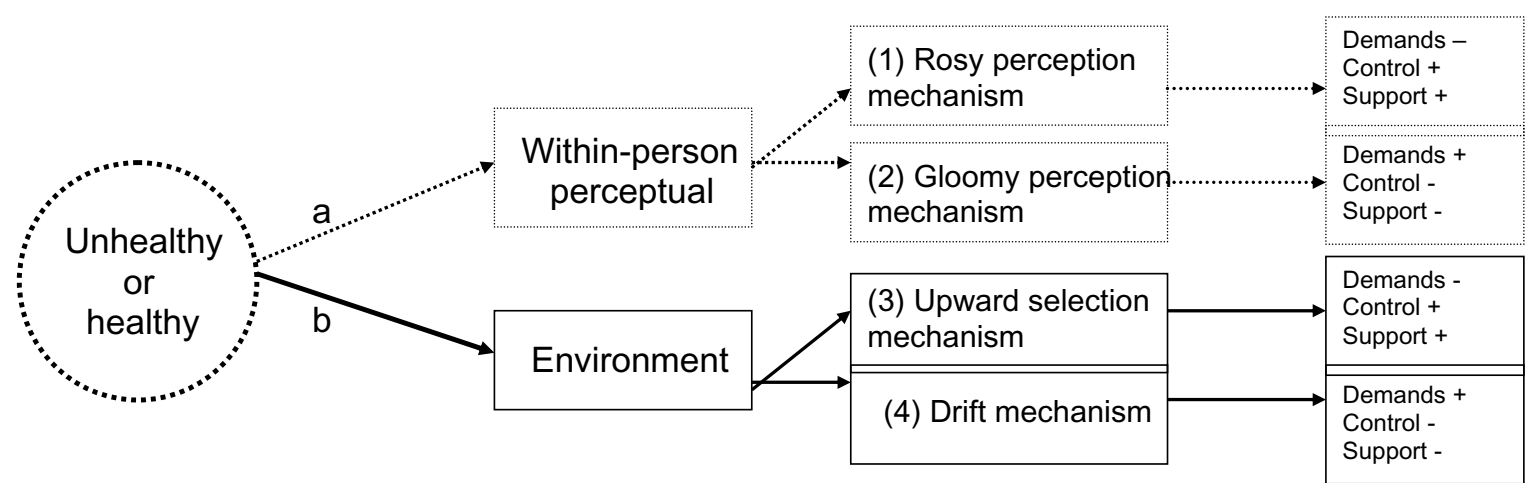

Figure 1. Four mechanisms for reversed effects of mental health on work. 
either real positive or negative changes in the work environment (environmental changes, corresponding with path $b$ in figure 1) or to changes of the evaluation of the same work environment (within-person changes, path a in figure 1) or due to combinations of the two.

Therefore, we have hypothesized that reversed causation can be explained by different processes within different subgroups. One way to explore these processes is to compare employees who remain in the same job with job changers. We assumed that reported DCS changes of employees working in the same psychosocial work environment (stayers) more likely reflect perceptual or within-person reversed effects than do DCS changes reported by workers who transfer to a different job. Furthermore, reported DCS changes of job changers will more likely reflect reversed (real) environmental effects of their mental health status than the changes reported by stayers. This is not to say that it is not possible that stayers and job changers experience combinations of these mechanisms. For example, an unhealthy job changer may transfer to a more-positive work environment (with more real job control) but, at the same time, may also have a rosier perception of the amount of support provided by his or her new colleagues. Since reversed causation implies an effect of time-1 mental health, we believe it is important to compare time-1 healthy versus unhealthy workers with respect to their DCS changes across time. In the discussion that follows, we present these mechanisms in greater detail.

\section{Four mechanisms for reversed causation}

\section{Within-person perceptual mechanisms}

We assumed that time-1 mental health status may change one's evaluation of the same job across time in several ways. First, positive re-evaluations of work characteristics can be explained by the assumption that workers color their perceptions of work characteristics in a rosier light (the rosy perception mechanism, mechanism 1 in figure 1). For instance, time-1 healthy workers can have more energy to work faster (compared with less energetic co-workers), and this energy can lead them to re-interpret their job demands as less demanding across time (22). Positive re-interpretation effects may also be explained by the fact that unhealthy employees have changed their aspirations and cognitions in order to accept their unfavorable work situation or that they have colored their perceptions in line with their expectations of the work environment [eg, as a result of a "cognitive dissonance" effect (23)]. Employees who have realized that they will not be able to improve their job or find a better job may have accepted their situation and may also have colored their perception in a rosier light ("after all, this job is not so bad"). In other words, we believe the rosy perception mechanism is accepted when (un)healthy stayers report significantly more favorable work characteristics across time (in line with the assumptions of the DCS model: significantly fewer job demands or more job control or social support (mechanism 1 in figure 1).

Employees may also perceive their work environment as more negative across time. Negative re-evaluation effects can be explained by the assumption that healthy workers perceive the same job as gloomier across time. In these situations, employees may even speak of "the daily grind of work". According to the person-environment (P-E) fit theory (24, p 86), these negative evaluation effects can be explained by a discrepancy between what the worker (P) wants (eg, a more-challenging work environment) and what the worker gets in his or her job (E). For instance, a teacher who has taught the same course for several years may perceive his or her job as less challenging than when he or she first taught the course.

Zapf et al (9) labeled the negative re-interpretation effect for unhealthy workers as the "true strain-stressor process", whereas Spector et al (25) spoke of the "stressor creation hypothesis" (in the context of negative affectivity). Since also other strain-stressor effects may operate (see figure 1), we have re-labeled this explanation as the gloomy perception mechanism. Unhealthy employees (eg, depressive workers) can also evaluate their environment more negatively and thus report less favorable work characteristics. These unhealthy workers have a gloomier perception of reality. We believe the gloomy perception mechanism is supported when (un)healthy stayers report a significant decrease in favorable work characteristics (ie, significantly more job demands or less job control or social support) across time (mechanism 2 in figure 1).

\section{Environmental change mechanisms}

Health status can also result in real changes in the work environment. One explanation for positive changes in the work environment draws on the occurrence of promotions among healthy workers. In this upward selection process, relatively healthier workers get promoted to more-challenging jobs (possibly experiencing more job control) or to less stressful jobs [with fewer job demands and more job control and social support (26, p 263)]. Job changes may also have positive environmental outcomes for unhealthy workers. For example, unhealthy workers may have successfully looked for refuge in a different job (17) and, accordingly, also moved upwards to a more favorable work environment. These unhealthy employees organize their jobs or positions 
differently or transfer to a less stressful job in order to create a less demanding work environment, characterized by, for instance, fewer demands or higher control and social support. We believe the upward selection mechanism is supported if a job change of a(n) (un)healthy worker results in a more-favorable work environment (ie, significantly fewer job demands or significantly more job control and social support) (mechanism 3 in figure 1).

Health effects can also result in negative changes in the work environment, as described by the drift mechanism of Zapf et al (9) and Frese (27). According to this mechanism, workers with poor health drift to less-favorable jobs. For instance, if for any reason the health of a worker deteriorates and he or she becomes unable to meet current job demands, the job has to be changed or the worker will leave the job (and find a less-favorable one). This downward selection process (28) can be understood as a derivative of the familiar healthy worker effect (29), namely, the assumption that only healthy workers are able to retain a certain job implies that unhealthy workers are unable to do so. Finally, negative work environment changes reported by healthy workers can also be explained from a downward selection effect or drift. For example, the new job is not what the employee expected, or he or she finds it hard to cope with the new job demands. We believe the drift mechanism is supported if (un)healthy job changers report a significant increase in negative work characteristics (ie, more job demands and less job control or social support (mechanism 4 in figure 1).

\section{Test of the four mechanisms for reversed causation}

Using our distinction between environmental changes and perceptual changes of the same work environment, we found the following four explanations for possible reversed effects of mental health on work: (i) a rosy perception mechanism, (ii) a gloomy perception mechanism, (iii) an upward selection mechanism, and (iv) a drift mechanism. (See figure 1.) One earlier study (17) tested several mechanisms for reversed effects [ie, the refuge mechanism, the drift mechanism, and "positive or negative direct effects" (comparable with our environmental mechanisms)] and found support for the refuge (an upward selection) mechanism and positive direct effects mechanism. However, one important limitation of this study was that the authors did not distinguish between different subgroups (eg, stayers versus job changers), whereas it would seem likely that several reversed causation mechanisms may be more valid for certain subgroups. For example, we assumed that re-evaluation or within-person mechanisms would be more likely for unhealthy or healthy workers who remain in the same job (stayers), whereas environmental change mechanisms may be more visible within subgroups that actually transfer to different jobs (job changers). Furthermore, the current theory concerning reversed causation indicates that unhealthy workers report relatively more negative (re-evaluation or environmental) changes in their work characteristics than healthy workers do [eg, the drift mechanism of Zapf et al (9) or the stressor creation hypothesis of Spector et al (25)], but we do not yet know whether this is true. In addition, earlier research in occupational health psychology has also emphasized the importance of subgroup analysis $(1,3,30,31)$, as it allows the exploration of multiple (reversed) causation mechanisms simultaneously. Consequently, in this study, we tested the different reversed causation mechanisms using subgroup analysis (distinguishing between healthy versus unhealthy workers and stayers versus job changers).

\section{Study population and methods}

Study population. We conducted our study within the framework of the four-phase prospective Dutch cohort study on musculoskeletal disorders, absenteeism, stress and health (SMASH). Altogether 1789 employees working in 34 companies, located throughout The Netherlands, participated. [See de Lange et al (30) for more information.] Both blue-collar jobs and white-collar jobs were selected. In each phase (ie, 1994, 1995, 1996, and 1997) the respondents completed a self-administered questionnaire, tapping concepts such as general work conditions, changes in the workplace, psychosocial work characteristics, psychosocial and physical health, and background factors.

The response rates were relatively high and varied from $84 \%(\mathrm{~N}=1742)$ at baseline to $85 \%(\mathrm{~N}=1473)$ in the third follow-up measurement. A nonresponse analysis revealed that dropouts tended to report more strain and less control across time, a common phenomenon in longitudinal research. [See Taris (32) for a review.] As a consequence, our results may reflect an underestimation of the true reversed effects of low mental health, as the relatively unhealthy workers dropped out across time.

Measures. Job demands were measured using a 5-item Dutch version of Karasek's (33) job content questionnaire (eg, "My job requires working very fast", 1 = strongly disagree", 4 = "strongly agree"). The reliability (Cronbach's alpha) of this scale varied from 0.65 to 0.72 across the phases of the study (median alpha $=$ $0.71)$. 
Consistent with Karasek's (33) conceptualization, job control was measured as the mean of two scales. Skill discretion was measured using a 5-item scale (eg, "My job requires that I learn new things"), and decision authority was measured using a 3-item scale (eg, "My job allows me to take many decisions on my own", 1 = "strongly disagree", 4 = "strongly agree"). The reliabilities of the job control scale ranged from 0.81 to 0.83 (median alpha $=0.83$ ).

Supervisors' social support was measured using a 4item Dutch version of Karasek's (33) job content questionnaire (eg, "My supervisor pays attention to what I say ", 1 = "strongly disagree", 4 = "strongly agree"). The reliability (Cronbach's alpha) of this scale varied from 0.82 to 0.88 across occasions (median alpha $=0.86$ ).

In line with Warr $(34,35)$, mental ill health was measured in terms of depressive mood. Warr $(34,35)$ suggested that "depression to enthusiasm" is one of the central affective dimensions of job-related mental health. Depressive mood is a common indicator of the "depression" dimension of job-related mental health (36), and it was measured using an 11-item Dutch version of the CES-D scale $(37,38)$ (eg, "The past two weeks I felt lonely", 1 = "hardly ever or never", 3 = "much or most of the time", higher scores reflecting higher levels of depressive mood). The reliability varied from 0.81 to 0.87 across occasions (median alpha $=$ $0.85)$.

Age, gender $(0=$ male, $1=$ female $)$, and education (five categories, ranging from primary or lower education to college or university education) were used as covariates in the analysis, because these variables are often related to our outcome variables $(2,39)$. We did not formulate substantive hypotheses concerning their effects. In addition, we controlled for time- 2 depressive mood, as we wanted to control for the possibility that the mental health status of the workers had changed during the follow-up period and had affected the (perceptions of) time- 2 work conditions differently from those of the time-1 phase.

Subgroup analyses. As already discussed, the reversed causation mechanisms hypothesized different effects for healthy and unhealthy stayers (merely indicating possible evaluation effects) and (un)healthy job changers (merely indicating possible environmental effects).

On all four occasions of the study, the employees were asked whether they had changed jobs over the preceding 12 months ("yes" for job-change groups and "no" for stayers) and whether their colleagues and supervisors changed over the preceding 12 months ("no" for stayers). As a consequence, our stayers reported no job changes and no changes in their colleagues and supervisors and therefore had a rather stable work environment.
To maximize the utility of the data, we selected all possible job changers and stayers across the four phases of the study and transformed their data into a twophase design, resulting in a before (new time-1: $\mathrm{N}_{\mathrm{T} 1}$ ) and after (new time-2: $\mathrm{N}_{\mathrm{T} 2}$ ) job-change measurement. For the stayers the $\mathrm{N}_{\mathrm{T} 1}$ and $\mathrm{N}_{\mathrm{T} 2}$ measurements were based on the first two phases, whereas for the job-change groups, these measurements were based on the first two phases (group 2), the second and third phases (group 3), and the third and fourth phases (group 4) of our data. Subsequently, the data of these job-change groups (groups 2, 3 and 4) were pooled, the result being a single data set with a pre- and postchange measurement for both the stayers and the job changers.

Using the depressive mood scores at $\mathrm{N}_{\mathrm{T} 1}$ and $\mathrm{N}_{\mathrm{T} 2}$ (using the median split method: median value $=1.45$ ), we classified healthy (mean $\mathrm{N}_{\mathrm{T} 1}=1.14, \mathrm{SD}=0.13$ ) versus unhealthy (mean $\mathrm{N}_{\mathrm{T} 1}=1.68, \mathrm{SD}=0.23$ ) employees. These groups differed significantly in their average depressive mood scores, the degree of difference indicating sufficient contrast between the groups. Subsequently, the health status and job-change information (stayer or job changer) was used to classify healthy versus unhealthy job changers and stayers.

After the listwise deletion of missing values, the sample included 1588 employees [66\% male; average age at baseline 35.9 (SD 8.7) years for the stayers and 34.0 (SD 8.5) years for the job changers]. The number of participants in each of the four groups was 161 for the unhealthy job changers, 88 for the healthy job changers, 804 for the unhealthy stayers, and 535 for the healthy stayers.

Statistical analysis. Structural equation modeling (40) was used to test normal and reversed causal effects between job demands, job control, social support of supervisors, and depressive mood across time. To examine the different causal relationships, we first tested a baseline model versus several nested (competing) models. The models were as follows: (i) $\mathrm{M}_{0}$ or baseline model, including temporal stabilities and synchronous (within-phase) effects of variables across time and controls for the influence of covariates and used as the reference model; (ii) $\mathrm{M}_{1}$ or normal causation model, $\mathrm{M}_{0}$ being extended with cross-lagged paths from the new time- 1 demands, control and social support of supervisors (hereafter, DCS) dimensions to the new time- 2 depressive mood; (iii) $\mathrm{M}_{2}$ or reversed causation model, $\mathrm{M}_{0}$ being extended with cross-lagged paths from the new time-1 depressive mood to the new time-2 DCS dimensions; and (iv) $\mathrm{M}_{3}$ or reciprocal causation model, $\mathrm{M}_{0}$ being extended with reciprocal cross-lagged paths (regular paths from model 1 and the reversed paths from model 2). 
Table 1 presents the fit indices for the baseline model and the competing structural models. This table shows that all of the structural models presented satisfactory fit indices [NNFI and GFI $\geq 0.90$, RMSEA $\leq 0.05$ (41)]. Moreover, we tested the chi-square differences for the nested structural models versus the baseline model (table 1, column 6). This analysis revealed whether the more complex models (ie, $\mathbf{M}_{1,2,3}$ ) had a better fit than the baseline model without lagged relationships between work and mental health $\left(\mathrm{M}_{0}\right)$. As model 1, 2, and 3 all fit the data significantly better than the baseline model, we also tested the chi-square difference between model 3 (the reciprocal causation model) and model 1 (normal causation model) and model 2 (reverse causation model) (column 7 in table 1).

Table 1 shows that the reciprocal causation model $\left(\mathrm{M}_{3}\right)$ presented the best fit for the data, not only in terms of the fit indices, but also relative to the three competing models. Significant normal negative cross-lagged effects were found from time-1 social support of supervisors to time- 2 depressive $\operatorname{mood}(\beta=-0.06 ; \mathrm{P}<0.05)$. A

Table 1. Fit indices for the stability model versus the nested (competing) causal structural models $(\mathrm{N}=1216)$. (NNFI = nonnormed fit index, GFI = goodness of fit index, RMSEA = rootmean-square error of approximation, $\chi^{2}=$ chi-square, $\Delta$ = change)

\begin{tabular}{lrrrrrrr}
\hline Model & $\chi^{2}$ & \multicolumn{1}{c}{$\begin{array}{c}\text { De- NNFI } \\
\text { gree } \\
\text { of free- } \\
\text { dom }\end{array}$} & & & GFI RMSEA & $\begin{array}{c}\Delta \chi^{2} \\
\text { com- } \\
\text { pared } \\
\text { to } \mathrm{M}_{0}\end{array}$ & $\begin{array}{c}\Delta \chi^{2} \\
\text { com- } \\
\text { pared } \\
\text { to } \mathrm{M}_{0}\end{array}$ \\
\hline Baseline $\left(\mathrm{M}_{0}\right)$ & $34.44^{* *}$ & 12 & 0.96 & 0.99 & 0.039 & & \\
Normal $\left(\mathrm{M}_{1}\right)$ & $18.55^{*}$ & 9 & 0.98 & 1.00 & 0.029 & $15.89^{* *}$ & $16.82^{* *}$ \\
Reversed $\left(\mathrm{M}_{2}\right)$ & $17.26^{*}$ & 9 & 0.98 & 1.00 & 0.027 & $17.18^{* *}$ & $15.53^{* *}$ \\
Reciprocal $\left(\mathrm{M}_{3}\right)$ & 1.73 & 6 & 1.02 & 1.00 & 0.00 & $32.71^{* *}$ & \\
\hline
\end{tabular}

${ }^{*} \mathrm{P}<0.05$.

${ }^{* *} P<0.01$ significant positive reversed cross-lagged effect was found for time- 1 depressive mood on time- 2 demands $(\beta=0.09 ; P<0.05)$. In addition, a significant negative reversed cross-lagged effect was found for time-1 depressive mood on time- 2 social support of supervisors $(\beta=-$ $0.06 ; \mathrm{P}<0.05)$.

To test the four different reversed causation mechanisms, we performed a separate 4 (group: healthy stayers versus unhealthy stayers versus healthy job changers versus unhealthy job changers $) \times 2$ (time: $\mathrm{N}_{\mathrm{T} 1}$ versus $\mathrm{N}_{\mathrm{T} 2}$ ) analysis of covariance (ANCOVA) for each work characteristic, with time as a within-participant factor, group as a between-participant factor, and age, gender and education as covariates. A significant group $\times$ time effect would indicate that the across-time development of the work characteristics differed as a function of group. If so, the follow-up analyses were performed to examine whether this change was in line with one of the four mechanisms.

\section{Results}

Table 2 presents the means, standard deviations, and correlations for the new time-1 $\left(\mathrm{N}_{\mathrm{T} 1}\right)$ and time- $2\left(\mathrm{~N}_{\mathrm{T} 2}\right)$ variables separately for the job changers and the stayers. The results of a two-group (stayers versus job changers) structural equation analysis showed that the null hypothesis, that the correlations among the variables were the same for the stayers and the job changers, had to be rejected $\left[\chi^{2}(50)=178.12, \mathrm{P}<0.01\right]$. As at least part of the correlations for these groups differed significantly, the reverse causation mechanisms had to thus be examined separately for each group.

Evidence for one or more reversed causation mechanisms. To test the four reversed causation mechanisms,

Table 2. Correlations, ${ }^{\text {a }}$ means, and standard deviations for the study variables of the stayers (upper diagonal, $\mathrm{N}=1006$ ) versus the job changers (lower diagonal, $\mathrm{N}=210)$. $\left(\mathrm{N}_{\mathrm{T} 1}=\right.$ new time $1, \mathrm{~N}_{\mathrm{T} 2}=$ new time 2)

\begin{tabular}{|c|c|c|c|c|c|c|c|c|c|c|c|c|c|c|c|}
\hline \multirow[t]{2}{*}{ Variables } & \multicolumn{2}{|c|}{ Stayers } & \multicolumn{2}{|c|}{ Job changers } & \multicolumn{11}{|c|}{ Variables ${ }^{a}$} \\
\hline & M & SD & M & SD & 1 & 2 & 3 & 4 & 5 & 6 & 7 & 8 & 9 & 10 & 11 \\
\hline $1 \mathrm{Age}^{\mathrm{b}}$ & 35.83 & 8.65 & 33.96 & 8.48 & 1.00 & -0.16 & -0.03 & 0.03 & 0.12 & 0.04 & -0.05 & 0.03 & 0.12 & 0.03 & -0.02 \\
\hline 2 Gender & 1.34 & 0.47 & 1.30 & 0.46 & -0.28 & 1.00 & 0.11 & 0.02 & -0.24 & 0.01 & 0.13 & 0.01 & -0.17 & 0.05 & 0.11 \\
\hline 3 Education ${ }^{c}$ & 20.68 & 1.12 & 2.89 & 1.16 & -0.04 & 0.24 & 1.00 & -0.06 & 0.21 & -0.03 & -0.01 & -0.06 & 0.17 & 0.00 & 0.00 \\
\hline $4 \mathrm{~N}_{\mathrm{T} 1}$ demands & 2.59 & 0.48 & 2.59 & 0.48 & 0.04 & 0.05 & 0.01 & 1.00 & -0.03 & -0.18 & 0.13 & 0.56 & -0.02 & -0.11 & 0.13 \\
\hline $5 \mathrm{~N}_{\mathrm{T} 1}$ control & 2.80 & 0.49 & 2.84 & 0.48 & 0.13 & -0.12 & 0.27 & -0.08 & 1.00 & 0.24 & -0.17 & -0.03 & 0.69 & 0.14 & -0.15 \\
\hline $6 \mathrm{~N}_{\mathrm{T} 1}$ supervisory support & 2.72 & 0.53 & 2.63 & 0.58 & -0.16 & 0.02 & -0.01 & -0.21 & 0.36 & 1.00 & -0.10 & -0.10 & 0.19 & 0.51 & -0.12 \\
\hline $7 \mathrm{~N}_{\mathrm{T} 1}$ depression & 1.32 & 0.33 & 1.31 & 0.29 & 0.01 & 0.12 & 0.04 & 0.18 & -0.17 & -0.26 & 1.00 & 0.15 & -0.15 & -0.10 & 0.49 \\
\hline $8 \mathrm{~N}_{\mathrm{T} 2}$ demands & 2.55 & 0.50 & 2.62 & 0.48 & 0.09 & 0.02 & 0.00 & 0.47 & -0.10 & -0.13 & 0.16 & 1.00 & -0.06 & -0.21 & 0.18 \\
\hline $9 \mathrm{~N}_{\mathrm{T} 2}$ control & 2.85 & 0.47 & 2.97 & 0.47 & 0.03 & -0.05 & 0.33 & -0.08 & 0.53 & 0.18 & -0.12 & -0.17 & 1.00 & 0.31 & -0.18 \\
\hline $10 \mathrm{~N}_{\mathrm{T} 2}$ supervisory support & 2.64 & 0.59 & 2.71 & 0.61 & -0.16 & 0.02 & 0.04 & -0.12 & 0.16 & 0.33 & -0.19 & -0.22 & 0.23 & 1.00 & -0.17 \\
\hline $11 \mathrm{~N}_{\mathrm{T} 2}$ depression & 1.32 & 0.32 & 1.34 & 0.34 & 0.03 & 0.05 & -0.01 & 0.08 & -0.19 & -0.23 & 0.55 & 0.30 & -0.25 & -0.24 & 1.00 \\
\hline
\end{tabular}

a Correlations of $\geq 0.09$ are significant at $P<0.05$.

${ }^{\mathrm{b}} 0=$ female, 1 = male.

c 1 = primary education or lower, 2 = lower vocational education, 3 = secondary education or middle vocational education, $4=$ higher vocational education; 5 = college or university education. 
we compared the across-time development of the work characteristics for the four groups (ie, healthy job changers, unhealthy job changers, healthy stayers, and unhealthy stayers). Table 3 presents the means and standard deviations of the work characteristics as a function of time and group. As this table shows, there was only a significant main effect of time for demands $[\mathrm{F}(1,1250)$ $=5.28, \mathrm{P}<0.05]$. Overall, the data showed a significant decrease in demands across time. The means for control and supervisory social support were stable across time.

The main effects of group were found for demands $[\mathrm{F}(3,1250)=4.78, \mathrm{P}<0.05]$, control $[\mathrm{F}(3,1255)=2.63$, $\mathrm{P}<0.05]$ and the social support of supervisors $[\mathrm{F}(3$, $1243)=5.85, \mathrm{P}<0.01]$. Tukey's test for the least significant differences (LSD) revealed that the pattern of effects was similar across the groups, as the unhealthy subgroups reported relatively more negative outcomes in terms of demands, control, and social support of supervisors and the healthy subgroups reported more positive outcomes. More specifically, the unhealthy job changers reported the highest level of $\mathrm{N}_{\mathrm{T} 2}$ demands and the lowest level of $\mathrm{N}_{\mathrm{T} 2}$ social support of supervisors in comparison with the other subgroups, whereas the unhealthy stayers reported the lowest level of control.

Significant interaction effects between time and group were found for demands $[\mathrm{F}(3,1250)=2.98$, $\mathrm{P}<0.05]$, control $[\mathrm{F}(3,1255)=3.86, \mathrm{P}<0.01]$, and social support of supervisors $[\mathrm{F}(3,1243)=4.04, \mathrm{P}<0.01]$. Table 3 shows the means for these interaction effects. To interpret these effects, we tested the time trends for each group separately. The effects for demands, control, and social support follow with reference to the four mechanisms.

Support for different mechanisms. The significant group $x$ time interaction effects for the social support of supervisors and demands support the mechanisms that reflect the evaluation effects. Figure 2 shows that only the unhealthy and healthy stayers (but not the job changers) reported significant differences in demands and the social support of supervisors across time. Both the unhealthy $[\mathrm{F}(1,628)=16.30, \mathrm{P}<0.01]$ and the healthy $[\mathrm{F}(1$, $439)=8.65, \mathrm{P}<0.01]$ stayers reported a significant decrease in job demands across time. Both healthy and unhealthy workers perceived their job demands more positively, and this finding indicated a rosy perception mechanism as they remained in the same job.

The significant effects for supervisory support suggest negative re-evaluation effects. Both the unhealthy and the healthy stayers reported significantly less supervisory support across time $[\mathrm{F}(1,625)=8.00, \mathrm{P}<0.01$, and $\mathrm{F}(1,436)=11.31, \mathrm{P}<0.01$, respectively]. Since the employees' work situations did not change (ie, they worked with the same supervisor), it is plausible that prior health status resulted in within-employee changes. Thus the significant decrease in social support indicates a gloomy perception mechanism for the (un)healthy workers.

The significant group $\times$ time effect for control revealed some support for environmental change mechanisms. More specifically, figure 2 shows that the healthy and unhealthy job changers reported significant positive increases in their scores on control across time $[\mathrm{F}(1$, $145)=5.54, \mathrm{P}<0.05$, and $\mathrm{F}(1,81)=14.41, \mathrm{P}<0.01$, respectively]. Hence both the unhealthy and the healthy job changers obtained more job control in their new job. These results indicated an upward selection mechanism for the unhealthy employees (ie, they successfully looked for refuge in a new job) and the healthy employees (who may have changed to a new job with more job control). However, no support was found for the drift mechanism.

Table 3. Means and standard deviations of the outcome variables as a function of time and group. (Group $1=$ unhealthy job changers, Group 2 = healthy job changers, Group 3 = unhealthy stayers, Group $4=$ healthy stayers, $N_{T 1}=$ new time $1, N_{T 2}=$ new time 2, MANOVA = multiple analysis of variance, NS $=$ not significant)

\begin{tabular}{|c|c|c|c|c|c|c|c|c|c|c|c|c|c|c|c|c|}
\hline \multirow[t]{3}{*}{ Variables } & \multicolumn{3}{|c|}{ Group 1} & \multicolumn{4}{|c|}{ Group 2} & \multicolumn{3}{|c|}{ Group 3} & \multicolumn{3}{|c|}{ Group 4} & \multicolumn{3}{|c|}{ MANOVA F-values } \\
\hline & \multicolumn{2}{|c|}{$\mathrm{N}_{\mathrm{T} 1}$} & \multirow{2}{*}{$\frac{\mathrm{N}_{\mathrm{T} 2}}{\text { Mean SD }}$} & \multirow{2}{*}{\multicolumn{2}{|c|}{$\frac{\mathrm{N}_{\mathrm{T} 1}}{\text { Mean SD }}$}} & \multicolumn{2}{|c|}{$\mathrm{N}_{\mathrm{T} 2}$} & \multicolumn{2}{|c|}{$\mathrm{N}_{\mathrm{T} 1}$} & $\mathrm{~N}_{\mathrm{T} 2}$ & \multicolumn{2}{|c|}{$\mathrm{N}_{\mathrm{T} 1}$} & \multirow{2}{*}{$\frac{\mathrm{N}_{\mathrm{T} 2}}{\text { Mean SD }}$} & \multirow[t]{2}{*}{ Time } & \multirow[t]{2}{*}{ Group } & \multirow{2}{*}{$\begin{array}{l}\text { Time } x \\
\text { group }\end{array}$} \\
\hline & Mean & SD & & & & Mean & SD & Mean & SD & Mean SD & Mean & SD & & & & \\
\hline Demands & 2.60 & 0.04 & $2.64 \quad 0.04$ & 2.58 & 0.05 & 2.55 & 0.05 & 2.64 & 0.02 & $2.55^{\text {a }} 0.02$ & 2.52 & 0.02 & 2.48 a 0.03 & $5.28^{\star b}$ & $4.78^{\star c} \mathrm{c}$ & $2.98^{\star} \mathrm{c}$ \\
\hline Control & 2.83 & 0.04 & 2.94 a 0.04 & 2.84 & 0.05 & $2.99 \mathrm{a}$ & 0.05 & 2.81 & 0.02 & $2.84 \quad 0.02$ & 2.88 & 0.02 & $2.89 \quad 0.02$ & $3.17, \mathrm{NS}^{\mathrm{d}}$ & $3.86^{\star \star} \mathrm{e}$ & $2.63^{\star \mathrm{e}}$ \\
\hline $\begin{array}{l}\text { Social } \\
\text { support of } \\
\text { supervisors }\end{array}$ & 2.53 & 0.05 & 2.640 .05 & 2.85 & 0.06 & 2.86 & 0.07 & 2.70 & 0.02 & $2.64^{\text {a }} 0.02$ & 2.77 & 0.03 & $2.67^{\text {a }} 0.03$ & $0.38, \mathrm{NS}^{\dagger}$ & $5.85^{\star \star f}$ & $4.04^{* \star g}$ \\
\hline
\end{tabular}

\footnotetext{
Significant time trend for subgroup: difference between $\mathrm{N}_{\mathrm{T} 2}$ and $\mathrm{N}_{\mathrm{T} 1}$ scores for a particular subgroup.

b $F(1,1250)$.

$F(3,1250)$.

d $F(1,1255)$.

e $F(3,1255)$.

f $F(1,1243)$.

g $F(3,1243)$.

* $P<0.05$.

** $P<0.01 ;$ F-values after control for age, gender, education, and depressive mood T2.
} 
Demands

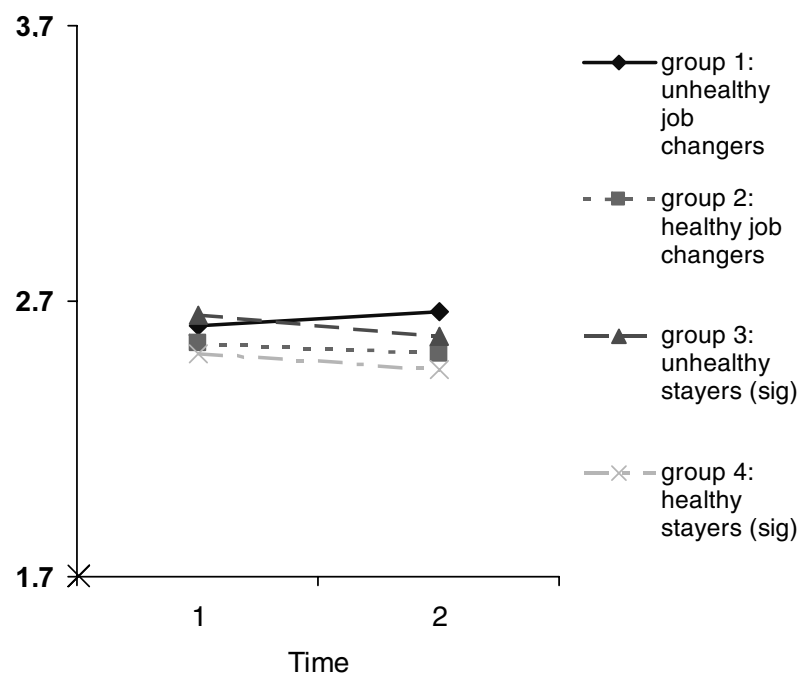

\section{Social support of supervisor}

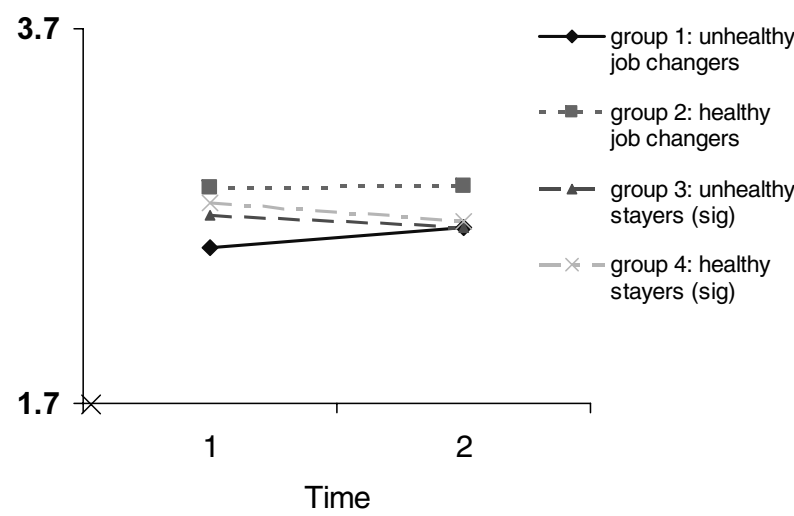

In summary, in addition to normal effects, our results provided evidence for reversed effects of depressive mood on the perception of work characteristics across time. The time- 1 healthy workers reported relatively more time- 2 positive work outcomes than the unhealthy workers (both the changers and the stayers). Furthermore, the reversed lagged effects of mental health on demands and social support was consistent with two within-person mechanisms, namely, the rosy perception mechanism and the gloomy perception mechanism. Finally, the reversed lagged effects of mental health on job control were consistent with an upward selection mechanism. No support was found for the drift mechanism.

\section{Discussion}

In this study, we attempted to shed more light on the mechanisms underlying reversed causation effects (ie,
Control

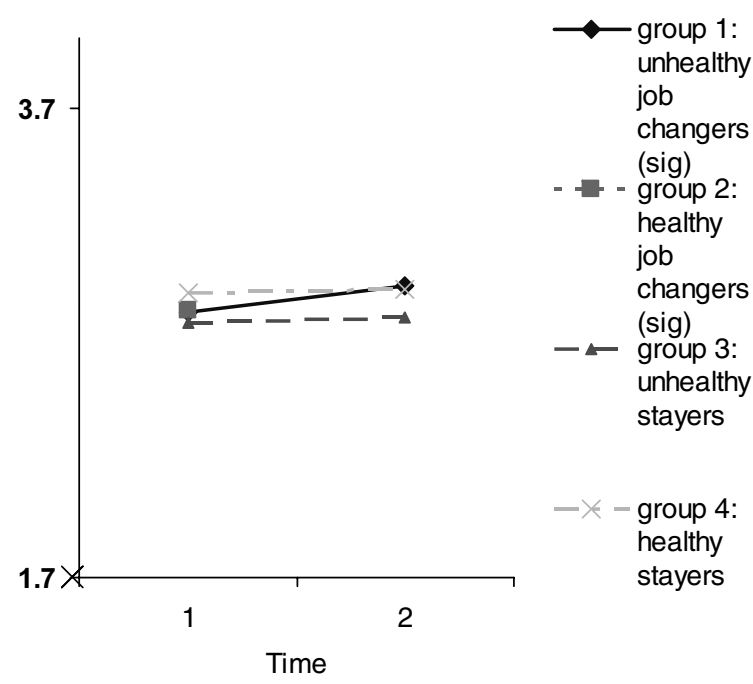

Figure 2. Changes in demands, control, and social support of supervisors for the different subgroups across time (new time 1 and new time 2). [sig = significant differences in means across time for the particular subgroup (associated F-values are presented in the text)]

effects of health status on work characteristics) in the context of a two-phase study among 1588 Dutch workers. We examined 1-year across-time reversed effects of depressive mood on psychosocial work characteristics and provided evidence for lagged effects of depressive mood on work that were in line with three reversed causation mechanisms. The results provided some support for both within-person and environmental change mechanisms. More specifically, the results for the stayers pointed at the following within-person change mechanisms: (i) the rosy perception mechanism (healthy and unhealthy workers perceived their job demands as more positive across time) and (ii) the gloomy perception mechanism (unhealthy and healthy workers perceived the same supervisors as less supportive). In addition, the reversed effects for job changers were in line with the upward selection mechanism (unhealthy and healthy workers successfully transferred to a less stressful work environment). Consequently, our data suggest different reversed causation mechanisms in explaining the reversed effect of mental health on work across time. 


\section{Study limitations and recommendations for future research}

Before discussing the implications of our findings, we must first address the most important limitations of our study. First, the findings were entirely based on self-reports. Thus our results may have been subject to biases [eg, due to personality traits such as negative affectivity $(31,42,43)]$. It would seem possible that not controlling for negative affectivity resulted in relatively high intercorrelations among the variables. Some researchers even claim that most of the variance in crosslagged relations between work characteristics and strain (measured by surveys) can be fully explained by negative affectivity (44). Initially, we decided not to control for negative affectivity in our analyses, as its moderating effects are not consistently found, and it is still unclear what the exact impact of partialing it out is $(24$, $25,45)$. To examine the possible impact of negative affectivity on our results, we conducted a post-hoc analysis. This analysis showed that the effects of depressive mood on the work characteristics reported in our study remained significant when negative affectivity was controlled. Thus it appears that controlling for negative affectivity did not severely bias our findings.

A second limitation follows from the longitudinal design of our study. Although longitudinal data are potentially much better suited for studying causal processes than cross-sectional data are (32), whether this benefit is fully utilized depends on the degree to which the time lag between the different phases of the study suits the process and etiology of the relationship between the research variables under study (7). For instance, the work characteristics of the job changers were measured an average of 6 months before and after the job change. Some previous research has shown that the first impact of job transition may be a "reality shock" or "honeymoon effect" (31) that may result in more extreme effects (which disappear after one has gotten used to the new job). At this point we do not know how long such effects may last. As we only employed a 1-year time lag, we do not know whether the results of the job changers are still under the influence of a "novelty phenomenon" or whether its impact has long vanished. Consequently, it is hard to assess whether our results present an under- or overestimation of the true reversed effects as a result of the time lag chosen. Multiphase designs with short intervals between the phases may be of more value in this respect. On the other hand, a problem of multiphase designs is the dropout of respondents across time. For example, our dropouts reported significantly more strain than the response group (indicating a restriction of range), and this difference indicates that the results found may reflect an underestimation of the true reversed causal lagged effects of mental health on work characteristics. Although it seems paradoxical, future research should try to follow-up these relatively more unhealthy dropouts across time. (Do they drift off to a more negative work environment?)

A third limitation of our study concerned the choice of the data for the group of stayers. The data for the preand posttest of the stayers were obtained in the time-1 and time- 2 phases. However, similar data could also have been obtained for the time- 2 to time- 3 or time- 3 to time-4 interval. To test whether our findings were dependent on the choice of the measurement occasions for the stayer group, we repeated our analyses for a different selection of measurement occasions (based on the time- 3 to time- 4 interval). Comparison of the aforementioned results and the new results revealed no significant differences. Thus it appears that the findings were not seriously affected by the choice of measurement points for the stayers.

Another limitation of our study was that we could not distinguish between voluntary (self-initiated) and involuntary (other-initiated) job changes. It would seem likely that the type of job change influences the results of these changes. For example, Kalleberg \& Mastekaasa (46) showed that a self-initiated job change is associated with positive work outcomes, while an employer-initiated job change is linked with negative outcomes. [See Baumeister et al (47) for similar results.] We could not control for these processes and were therefore unable to study their possible impact. It is possible that the positive outcomes of the job changers found in this study can be attributed to the fact that most of the job changes were self-chosen. It is therefore important that future research distinguishes between self-initiated or otherinitiated job changes in testing the explanations for reversed effects that involve real job changes, as some of the mechanisms discussed in our study assumed particular types of job changes. For example, the drift hypothesis of Zapf et al (9) seems to assume that many of the changes that lead to a worsening of the work environment are involuntary and initiated by others. Conversely, the refuge mechanism of Garst et al (17), an example of an upward selection mechanism, suggests that self-initiated changes are of primary importance. In this mechanism, unhealthy workers actively seek to improve their job characteristics. Thus it would seem desirable to examine whether particular types of job changes can be linked to particular reversed causality mechanisms.

In addition, we recommend that future research collect more (qualitative and objective) information about the type of job transfers and the work environment of the stayers to disentangle further the different reverse causation mechanisms. Post-hoc analyses of our job changers revealed that most of the healthy and unhealthy job changers reported job transfers to comparable jobs. More specifically, of the healthy job changers, $73.3 \%$ 
reported that the new job was comparable with their former job, compared with $76.1 \%$ of the unhealthy job changers. Consequently, we cannot conclude that the job transfers resulted in significantly different jobs, but we need more information about the type of job transfer to draw stronger conclusions for this subgroup. In addition, we have good reason to believe that the results of our selected stayers (with a stable work environment) provided more information about perceptual reversed effects than for the job changers, but we cannot fully exclude the possibility that the stayers did experience real changes in their work environment (eg, a supervisor that provided less support across time) and that the job changers did not experience perceptual effects (eg, perceive their new supervisor to be more positively in line with their expectations).

\section{Study implications}

Presumably the most interesting finding of our study is that no less than three out of the four reversed causation mechanisms received some support. Only the drift hypothesis of Zapf et al (9) (assuming that unhealthy and healthy workers drift to worse jobs) was not supported. One explanation for the absence of support for this mechanism is that workers who voluntarily accept another job because they expect to end up better off will presumably find it difficult to admit that they are worse off. Denial of the adverse consequences of transferring to another job may thus be considered a self-serving mechanism that protects one's self-esteem (48). It is also possible that the dropouts in this study (with more strain complaints) would provide more evidence for this mechanism.

Regarding the mechanisms that were supported, it is interesting to see that none of them received strong support; all three mechanisms received support for only one of the three work characteristics included in the study. This finding suggests that no one mechanism in particular stands out as the most important explanation for effects from strain on work characteristics. Furthermore, the patterns of effects did not differ for the healthy versus unhealthy employees nor did the within-person versus environmental mechanisms (2 versus 1 mechanism supported, respectively).

It is noteworthy that relatively strong improvements in job control only occurred for the job changers, irrespective of their health status. In other words, a change of job appears to offer a good possibility to improve job control. In this sense, transferring to a different job may be an effective way to improve one's work situationfor both healthy and unhealthy workers. The fact that both groups seem to profit from a job change was somewhat surprising, because earlier research suggested that unhealthy (ie, depressive) workers are less able to secure positive outcomes from a job change than others (20). It would seem possible, however, that socioeconomic circumstances influence the degree to which workers (whether they are healthy or not) can improve their work situation. The present study was conducted when the Dutch economy was still booming and thus offered job seekers good opportunities to find better jobs. However, the results may be differ in times of economic hardship.

The findings of our study show that there is no single mechanism that accounts for the effects of health on work characteristics. They suggest, therefore, that the relationship between health and work does not hold for everyone in the same way (22). As Semmer (24) pointed out: "People differ in the probability of encountering stressors, depending on their social environment but also on their own behaviour, as some stressors may be self-created [p 83]". From a practical point of view, our results therefore show that there is no general explanation that can be applied to every worker. Another finding that will interest employers and organizational psychologists alike is that our results showed that finding new employment can result in higher levels of job control for both healthy and unhealthy workers.

From a theoretical point of view, our results emphasize the benefits of including reversed effects in conceptualizing the relationships between work and (mental) health. In line with earlier longitudinal research, our results show that worklife is more dynamic than most work stress models convey; work not only has an impact on health, but health also has an impact on work. This reversed effect should be included in work stress models, like the demand-control-(support) model. Karasek \& Theorell (2, p 9) acknowledged this limitation of their model and stated that their model should not only account for objective work characteristics, but also for the perceptions of employees. They formulated a dynamic, integrated environment and person-based version of the demand-control model. Our results show that this dynamic model suits the etiology of work stress better than the original demand-control-(support) model, which only emphasized the "objective" work environment.

Acknowledging the existence of reversed effects is not enough. We also need to understand these effects. This study is one of the first longitudinal studies theorizing about the mechanisms that account for the reversed effects of (mental) health on work, and it distinguished four mechanisms that may explain reversed effects. Indeed, we believe that the main contribution of our study lies in the fact that it proposes (i) a conceptual framework for analyzing the effects of health on work characteristics and (ii) methods of testing the mechanisms distinguished within this framework. Our study shows that further research on reversed causality is 
needed. In this sense, we hope that our study will inspire new longitudinal research on the causal mechanisms underlying the effects of health on work.

\section{Acknowledgments}

This study was partly financially supported by the Dutch Ministry of Social Affairs and Employment; The Dutch Ministry of Public Health, Welfare, and Sports; and the Dutch National Institute for Social Security.

\section{References}

1. Taris T, Kompier M. Challenges of longitudinal designs in occupational health psychology [editorial]. Scand J Work Environ Health 2003;29(1):1-4.

2. Karasek R, Theorell T. Healthy work: stress, productivity, and the reconstruction of working life. New York (NY): Basic Books; 1990.

3. de Lange AH, Taris TW, Kompier MAJ, Houtman ILD, Bongers PM. "The very best of the millennium": longitudinal research and the demand-control-(support) model. J Occup Health Psychol 2003;8:282-305.

4. Van der Doef MP, Maes S. The job demand-control(-support) model and psychological well-being: a review of 20 years of empirical research. Work Stress 1999;13:87-114.

5. Hurrell JJ, Nelson DL, Simmons BL. Measuring job stressors and strains: where we are, and where we need to go. J Occup Health Psychol 1998;3:368-89.

6. Tennant C. Work-related stress and depressive disorders. J Psychosom Res 2001;51:697-704.

7. de Lange AH, Taris TW, Kompier MAJ, Houtman ILD, Bongers PM. The relationships between work characteristics and mental health: examining normal, reversed, and reciprocal relationships in a 4-wave study. Work Stress 2004;18:149166.

8. Dormann C, Zapf D. Social stressors at work, irritation, and depressive symptoms: accounting for unmeasured third variables in a multi-wave study. J Occup Organ Psychol 2002;75:33-58.

9. Zapf D, Dormann C, Frese M. Longitudinal studies in organizational stress research: a review of the literature with reference to methodological issues. J Occup Health Psychol 1996:1:145-69.

10. Kohn ML, Schooler C. Job conditions and personality: a longitudinal assessment of their reciprocal effects. Am J Sociol 1982;87:1257-86.

11. Marcelissen FHG, Winnubst JAM, Buunk B, de Wolff CJ. Social support and occupational stress: a causal analysis. Soc Sci Med 1988;26:365-73.

12. Bakker AB, Schaufeli WB, Sixma HJ, Bosveld W, van Dierendonck D. Patient demands, lack of reciprocity and burnout: a five-year longitudinal study among general practitioners. J Organ Behav 2000;21:425-41.

13. Jonge J de, Dormann C, Janssen PPM, Dollard MF, Landeweerd JA, Nijhuis FJN. Testing reciprocal relationships between job characteristics and psychological well-being: a cross-lagged structural equation model. J Occup Organ Psy- chol 2001;74: 29-46.

14. Leiter MP, Durup MJ. Work, home and in-between: a longitudinal study of spillover. J Appl Behav Sci 1996;32:29-47.

15. Mills LB, Huebner ES. A prospective study of personality characteristics, occupational stressors, and burnout among school psychology practitioners. J School Psychol 1998; 36:103-20.

16. Moyle P. Longitudinal influences of managerial support on employee well-being. Work Stress 1998;12:29-49.

17. Garst H, Frese M, Molenaar PCM. The temporal factor of change in stressor-strain relationships: a growth curve model on a longitudinal study in East Germany. J Appl Psychol 2000;8:417-38.

18. Glickman L, Tanaka JS Chan E. Life events, chronic strain, and psychological distress: longitudinal causal models. J Commun Psychol 1991;19:283-305.

19. Prosser D, Johnson S, Kuipers E. Perceived sources of work stress and satisfaction among hospital and community mental health staff, and their relation to mental health, burnout, and job satisfaction. J Psychosom Res 1997;43:51-9.

20. Taris TW, Bok IA, Caljé DG. On the relation between job characteristics and depression: a longitudinal study. Int J Stress Manage 1998;5:157-67.

21. Taris TW. The mutual effects between job resources and mental health: a prospective study among Dutch youth. Genet Soc Gen Psychol Monogr 1999;125:433-50.

22. Fletcher BC. A fit approach to work stress and health. In: Schrabracq MJ, Winnubst JAM, Cooper CL, editors. The handbook of work \& health psychology. Chichester (United Kingdom): John Wiley \& Sons Ltd; 2003. p 549-568.

23. Festinger L. A theory of cognitive dissonance. Evanston (IL): Row, Peterson; 1957.

24. Semmer NK. Individual differences, work, stress and health. In: Schrabracq MJ, Winnubst JAM, Cooper CL, editors. The handbook of work \& health psychology. Chichester (United Kingdom): John Wiley \& Sons Ltd; 2003. p 83-120.

25. Spector PE, Zapf D, Chen PY, Frese M. Why negative affectivity should not be controlled in job stress: don't throw out the baby with the bath water. J Organ Behav 2000;21:97-5.

26. Ganster DC, Schaubroeck J. Work stress and employee health. J Manage 1991;17:235-71.

27. Frese M. Stress at work and psychosomatic complaints: a causal interpretation. J Appl Psychol 1985;70:314-28.

28. Ettner SL, Grzywacz JG. Workers' perceptions of how jobs affect health: a social ecological perspective. J Occup Health Psychol 2001;6:101-13.

29. Marmot MG, Madge N. An epidemiological perspective on stress and health. In: Kasl SV, Cooper CL, editors. Research methods in stress and health psychology. New York (NY): John Wiley \& Sons; 1987. p 3-26.

30. de Lange AH, Taris TW, Kompier MAJ, Houtman ILD, Bongers PM. The effects of stable and changing demandcontrol histories on worker health. Scand J Work Environ Health 2002;28(2):94-108.

31. Frese M, Zapf D. Methodological issues in the study of work stress: objective vs subjective measurement of work stress and the question of longitudinal studies. In: Cooper CL, Payne R, editors. Causes, coping and consequences of stress at work. Chichester (United Kingdom): John Wiley \& Sons Ltd; 1988. p 375-411.

32. Taris TW. A primer in longitudinal data analysis. London: Sage; 2000.

33. Karasek RA. Job content instrument: questionnaire and user's guide. Los Angeles (CA): Department of Industrial and Sys- 
tems Engineering, University of Southern California; 1985.

34. Warr PB. Work, unemployment, and mental health. Oxford: Oxford University Press; 1987.

35. Warr PB. A conceptual framework for the study of work and mental health. Work Stress 1994;8:84-97.

36. Van Horn JE, Taris TW, Schaufeli WB, Schreurs PJG. The structure of occupational well-being: a study among Dutch teachers. J Occup Organ Psychol. In press.

37. Radloff LS. The CES-D scale: a self-report depression scale for research in the general population. Appl Psychol Meas 1977;1:385-401.

38. Kohout FJ, Berkman LF, Evans DA, Cornoni-Huntley J. Two shorter forms of the CES-D depression symptoms index. J Aging Health 1993;5:179-93.

39. De Jonge J, Kompier MAJ. A critical examination of the Demand-Control-Support Model from a work psychological perspective. Int J Stress Manage 1997;4:235-58.

40. Jöreskog KG, Sörbom D. Lisrel-8 (user's manual). Chicago (IL): Scientific Software; 1993.

41. Byrne BM. Structural equation modeling with AMOS. Mahwah (NJ): Lawrence Erlbaum; 2002.

42. Schnall PL, Landsbergis PA, Baker D. Job strain and cardiovascular disease. Annu Rev Public Health 1994;15:381-411.
43. Kristensen TS. Job stress and cardiovascular disease: a theoretical critical review. J Occup Health Psychol 1996;3:24660.

44. Brief AP, Burke MJ, George JM, Robinson B, Webster J. Should negative affectivity remain an unmeasured variable in the study of job stress? J Appl Psychol 1988;73:193-8.

45. Karasek R, Brisson C, Kawakami N, Houtman I, Bongers P, Amick B. The Job Content Questionnaire: an instrument for internationally comparative assessments of psychosocial job characteristics. J Occup Health Psychol 1998;3:322-55.

46. Kalleberg AL, Mastekaasa A. Satisfied movers, committed stayers: the impact of job mobility on work attitudes in Norway. Work Occup 2001;28:183-209.

47. Van der Velde MEG, Feij JA. Change of work perceptions and work outcomes as a result of voluntary and involuntary job change. J Occup Organ Psychol 1995;68:273-90.

48. Baumeister RF, Dale K, Sommer KL. Freudian defense mechanisms and empirical findings in modern social psychology: reaction formation, projection, displacement, undoing, isolation, sublimation, and denial. J Personality 1998;66:1081124.

Received for publication: 19 December 2003 